\title{
An E-Textile Respiration Sensing System for NICU Monitoring: Design and Validation
}

\author{
Gozde Cay $^{1}$ (D) . Vignesh Ravichandran ${ }^{1} \cdot$ Manob Jyoti Saikia $^{1,5} \cdot$ Laurie Hoffman $^{3} \cdot$ Abbot Laptook $^{3}$. \\ James Padbury ${ }^{3}$. Amy L. Salisbury ${ }^{3,4}$. Anna Gitelson-Kahn ${ }^{6} \cdot$ Krishna Venkatasubramanian $^{2}$ - Yalda Shahriari ${ }^{1}$. \\ Kunal Mankodiya ${ }^{1}$
}

Received: 6 December 2020 / Revised: 16 April 2021 / Accepted: 2 May 2021 / Published online: 17 July 2021

(C) The Author(s), under exclusive licence to Springer Science+Business Media, LLC, part of Springer Nature 2021

\begin{abstract}
The world is witnessing a rising number of preterm infants who are at significant risk of medical conditions. These infants require continuous care in Neonatal Intensive Care Units (NICU). Medical parameters are continuously monitored in premature infants in the NICU using a set of wired, sticky electrodes attached to the body. Medical adhesives used on the electrodes can be harmful to the baby, causing skin injuries, discomfort, and irritation. In addition, respiration rate (RR) monitoring in the NICU faces challenges of accuracy and clinical quality because RR is extracted from electrocardiogram (ECG). This research paper presents a design and validation of a smart textile pressure sensor system that addresses the existing challenges of medical monitoring in NICU. We designed two e-textile, piezoresistive pressure sensors made of Velostat for noninvasive RR monitoring; one was hand-stitched on a mattress topper material, and the other was embroidered on a denim fabric using an industrial embroidery machine. We developed a data acquisition system for validation experiments conducted on a high-fidelity, programmable NICU baby mannequin. We designed a signal processing pipeline to convert raw time-series signals into parameters including RR, rise and fall time, and comparison metrics. The results of the experiments showed that the relative accuracies of hand-stitched sensors were 98.68 (top sensor) and 98.07 (bottom sensor), while the accuracies of embroidered sensors were 99.37 (left sensor) and 99.39 (right sensor) for the $60 \mathrm{BrPM}$ test case. The presented prototype system shows promising results and demands more research on textile design, human factors, and human experimentation.
\end{abstract}

Keywords Respiration monitoring $\cdot$ E-textiles $\cdot$ Textile pressure sensors $\cdot$ NICU $\cdot$ Baby monitoring

Gozde Cay

gozdecay@uri.edu

1 Department of Electrical, Computer, and Biomedical Engineering, University of Rhode Island, Kingston, RI, USA

2 Department of Computer Science and Statistics, University of Rhode Island, Kingston, RI, USA

3 Pediatrics, Women and Infants Hospital, Providence, RI, USA

4 School of Nursing, Virginia Commonwealth University, Richmond, VA, USA

5 Center for Applied Brain and Cognitive Sciences, Tufts University, Medford, MA, USA

6 Department of Textiles, Rhode Island School of Design, Providence, RI, USA

\section{Introduction}

In 2018, WHO reported that 15 million babies are born preterm (before 37 completed weeks of gestation) globally, and this number is rising [1]. Preterm infants are at a significantly higher risk of medical and surgical morbidities in comparison to babies born at term ( $>37$ weeks). Therefore, preterm infants are specially cared in Neonatal Intensive Care Units (NICU) for continuous medical monitoring of respiration rate (RR), heart rate (HR), electrocardiogram (ECG), and blood oxygen saturation ( $\mathrm{SpO} 2-$ also known as pulse oximetry) [2]. Wired electrode sensors are attached to the chest and extremities of the infant for medical monitoring and pose several 
challenges. The challenges with current, standard respiration monitoring:

- Lack of direct measurement: While airflow sensors are the most accurate respiration monitoring technique, they may cause discomfort and are less well tolerated by preterm babies [3]. Therefore, infant respiration signals are generally extracted from ECG and pulse oximetry signals. Algorithms to extract respiration rate from these vital signs were developed using datasets taken from adult or child respiration values so they may not accurately represent the respiration signals from infants [4].

- Artifacts and false alarms: Additionally, optical blood oxygenation and heart rate sensors are significantly vulnerable to motion sensing artifacts such as limb movements, crying, coughing, and handling of the infant [5].

- Skin injuries: It is not uncommon for preterm infants to experience skin injuries and discomfort due to the adherent wired electrodes of ECG and $\mathrm{SpO} 2$ that stay connected to the body for long periods. Medical adhesives used in these electrodes may harm the underdeveloped and fragile skin of preterm infants [6]. The risk of neonatal skin injuries in NICU is as high as 43.1 percent [7]. Several large studies performed on newborn infants reported skin breakdown, pressure injuries, and skin-stripping because of the fixation, pressure, and removal of medical adhesives [8-12].

To address the challenges of skin injuries and poor respiration monitoring technology, we have pursued research to develop an unobtrusive respiratory monitoring system that is made of smart textile pressure sensors that are soft and comfortable to the fragile skin of preterm babies. The goal of this study was to design and validate well-tolerated textile sensors for accurately monitoring the respiratory changes of babies in the NICU. As shown in Figure 1, the textile sensor system includes a $2 \times 1$ fabric sensor grid to capture the respiration movement, a data acquisition system to preprocess and store signals, and a signal processing pipeline to compute the respiration parameters.

\section{Background and State-of-Art}

\subsection{Neonatal Intensive Care Unit (NICU)}

Preterm infants are categorized based on gestation age [a commonly used term to describe how far along the pregnancy is]: a) moderate to late preterm (32-37 weeks); b) very preterm (28-32 weeks); c) extremely preterm (less than 28 weeks). Preterm babies who are born before 37 weeks of pregnancy, have low birth weight (less than 5.5 pounds), have a great risk of medical problems such as breathing difficulty, heart problems, infections, birth defects, twins, triplets, or other multiples and are admitted to NICU [13]. In current NICU settings, the vital signs such as heart rate, respiration rate, and blood oxygen level are monitored with traditional electrodes and sensors. The respiration of the baby is monitored with an ECG system and respiration rate is extracted from ECG signals. The equipment used in NICU is described in Table 1.

While NICU equipment is essential, there is additional equipment for babies who have serious breathing problems. An endotracheal tube (ET) is a tube, which is placed through the baby's mouth or nose into the trachea. It then connects to a mechanical ventilator. Respirators or mechanical ventilators are used to help babies who do not breathe effectively on their own [14]. As shown in the Table, NICUs currently use wired electrode sensors attached to the chest and extremities. These standard electrodes suffer from a number of challenges, including skin injuries to infants due to long-term use of electrode adhesives as well as frequent false or non-actionable alarms due to
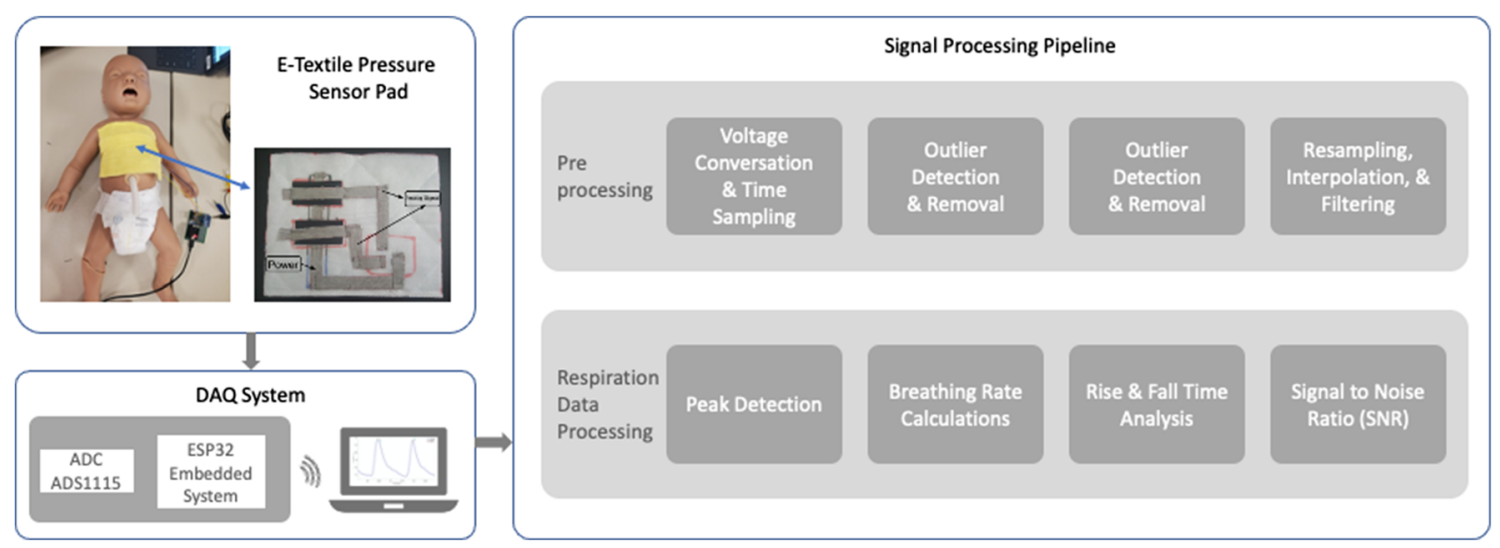

Figure 1 An overview of the proposed smart textile sensor system for NICU 
Table 1 A list of common NICU medical monitoring devices

\begin{tabular}{|c|c|c|}
\hline Equipment & Description & Sensor \\
\hline Heart or cardiorespiratory monitor & To display baby's heart and breathing rates and patterns & $\begin{array}{l}\text { Adhesive patches on the skin of } \\
\text { the baby's chest and abdomen }\end{array}$ \\
\hline Blood pressure monitor & To monitor the blood pressure of the baby & $\begin{array}{l}\text { Smaller version of traditional } \\
\text { cuff placed around the baby's } \\
\text { upper arm or leg }\end{array}$ \\
\hline Temperature probe & $\begin{array}{l}\text { To monitor baby's temperature } \\
\text { and regulate the heat needed to } \\
\text { keep the baby warm. }\end{array}$ & $\begin{array}{l}\text { Temperature probe placed on the } \\
\text { baby's skin with an adhesive } \\
\text { patch }\end{array}$ \\
\hline Pulse oximeter & To monitor the oxygen level in baby's blood & A tiny light taped to the baby's foot or hand \\
\hline
\end{tabular}

loosely connected electrode leads and drying contacts [15]. Therefore, it is important to make improvements over wired, sticky electrodes. There are research studies, which focus on contactless NICU monitoring. Due to the ongoing needs and limitations of the current standard monitoring equipment used in NICUs, recent research has explored alternative technologies to address these issues.

\subsection{Research on NICU Technologies}

Chung and his colleagues developed a binodal, wireless epidermal electronic system (EES) for ECG and SpO2 monitoring [16]. The ECG was mounted on the chest or back, and PPG was mounted on foot. The sensors communicated via NFC. The EES was tested on a healthy neonate and twenty-one premature babies. They also used conventional NICU monitoring as a gold standard. The results showed that the mean difference is -0.17 beats per minute for heart rate and 0.76 breaths per minute for respiratory rate, and 1.02 percent for $\mathrm{SpO} 2$. Although this is a completely wireless system, it still uses the medical adhesives on the electrodes, similar to conventional ECG electrodes.

Atallah et al. developed a mattress pad embedded with capacitive ECG sensors to monitor ECG activity in NICU [17]. They placed the mattress pad at the bottom of the crib mattress. To evaluate their system, they collected data from fifteen neonates at around 75 hours after birth. They also used the traditional ECG as ground truth. Although they demonstrated similar results with traditional ECG, the capacitive sensors still had connectivity and decoupling problems.

Sato et al. developed a piezoelectric transducer (PZT) sensor for noninvasive cardiorespiratory monitoring [18]. They placed the PZT sensor under a folded towel under the baby. To evaluate their system, they collected data from 27 neonates for ECG signals and 11 neonates for respiration signals in two settings. Brief assessments recorded 1- $\min$ data, and long assessments were recorded for 1-9 days for long-term data.
Their results showed that the PZT sensor had average correlation coefficients of $0.92 \pm 0.12$ and $0.95 \pm 0.02$ between ECG/IPG for the brief assessment. During the long assessments, the HR was detected approximately 10 lower than ECG, and the respiration rate was detected $95.9 \pm 4.0$ by PZT sensor, while IPC detected $95.3 \pm 3.5$ (total time of successful BR detection/total measurement time). Although the PZT sensor showed good performance, it still had mechanical-ventilation noise, which was unresolved.

Joshi et al. developed a system, which includes a filmlike pressure sensor placed between the mattress and the bedding [3]. Chest impedance and ballistographic signals were extracted from this pressure sensor to monitor the breathing rate. To evaluate the system performance, they collected data from 10 preterm babies. The chest impedance signal showed a significant correlation between the respiration rate derived from the ballistographic signal with $r=0.74$. They demonstrated that the respiration rate derived from the chest impedance signal was more unstable and prone to sudden increases and decreases compared to ballistographic signals.

Raj et al. developed a continuous respiratory rate monitoring system [19]. They used a 3-axis accelerometer to monitor the respiration rate. To evaluate their system, they collected data from 10 neonates. Clinicians directly observed and counted inhalation and exhalation as a gold standard measure. The results showed that their system had a correlation coefficient of 0.974 with direct observation. Although the system was wireless, they still used the adhesives to put the system on the baby's abdomen.

Hariyanti et al. designed a wearable fiber optic respiration sensor [20]. They used a bending optical fiber integrated into an elastic material and attached this sensor to the outside of an infant's diaper. The respiration rate was extracted from the changes in the intensity of light received by the photodiode. To evaluate their system performance, they used a ventilator machine to simulate a baby's breathing data. Their results showed that the sensor measured the respiratory rate with an error of 0.25 . Ambili et al. designed 
a system which monitors the respiration rate using raybaby (camera system) and EarlySense (piezo-electric sensor placed under the mattress) devices [21]. To evaluate the system, they collected 760 hours of data. Their results showed 98 percent accuracy of breathing rate monitoring in preterm babies.

Sun et al. evaluated two automated pipelines to estimate respiration rate from video images [22]. They evaluated optical flow-based method and deep learning-based flow estimation on videos of five premature babies. They extracted the respiration data from the chest impedance on the videos. Their results showed that the correlation coefficients were 0.70 and 0.74 for the optical flow- and the deep flow based methods respectively while the average root mean-squared errors were 6.10 and 4.55 .

Braun et al. developed an algorithm to monitor the respiration rate in real-time using a video camera [23]. They tested their algorithm on 16 healthy adults by performing guided breaths and handgrip events. They also used RGB color and NIR cameras in light and dark settings. They also used a thoracic strain gauge belt as reference. Their algorithm resulted with an error of $0.2 \pm 2.3 \mathrm{bpm}$ when compared to the reference measure.

\subsection{Smart Textiles in the NICU}

Smart textiles or e-textiles are fabrics embedded with electronics to enable conductivity or the ability to use them with various technologies. They can be used for different sensing technologies such as pressure [24], temperature [25], and flex [26].

The smart textiles can be divided into three groups:

- Passive smart textiles are generally sensors designed to sense the environment,

- Active smart textiles have two functions including sensing the environment as sensors and reacting to it as actuators

- Very smart textiles have three functions including sensing, actuation, and adaptation.

To turn regular textiles to smart textiles, there have to be two components, a sensor and an actuator.These two components are completed with a processing unit to drive sensors and collect data [27]. We have identified a few important research studies on smart textiles for neonatal applications.

Bouwstra and colleagues developed a smart jacket for neonatal monitoring [28]. This design aims to provide continuous monitoring of vital functions when the neonate is inside the incubator or in the parents' EMA during kangaroo mother care. They created textile ECG patches embedded in the fabric jacket. They tested their system on two subjects. The results showed that they successfully obtained the QRS complex from the signal.

Piccini and colleagues developed a Biosensor belt to monitor ECG and chest inflations [29]. They used conductive yarns to create electrodes and pathways for ECG acquisition and a textile extensometer suitable for measuring chest dilatations. The belt was developed with embedded sensors and transducers for monitoring the heart rate, breathing rate, body movements, and temperature. They collected data from four babies. They also used a commercial pulse oximeter.

Chen and colleagues developed a wearable belt for temperature monitoring in NICU [30]. As the temperature sensor, they used an NTC sensor that satisfies the accuracy of 0.1 degrees Celcius and the dimension requirements. The belt itself was created from bamboo textiles. According to feedback from healthcare providers, they placed the belt above the liver. The belt was tested on a premature baby for 45 minutes. They also used the conventional NICU sensor as the gold standard. The results showed that their belt monitored the temperature with 0.1 error.

Chen et al. developed a wearable multi-sensor platform for neonatal monitoring [31]. They designed a vest that included a stretching sensor for respiration monitoring, textile electrodes for ECG monitoring and an IMU sensor for movement monitoring. To evaluate the performance of respiration monitoring, they first tested the sensor on an adult with conventional PSG belt. The correlation coefficient between the RR derived from stretching sensor and the RR derived from PSG system was found greater than 0.8. They also tested the system on 15 neonates and the correlation coefficient between the RR derived from stretching sensor and the RR derived from PSG system was found as 0.969 .

\subsection{Limitations of Current (Recent) Research}

After observing monitoring in a state-of-the-art NICU, especially for respiratory signals, we realized that most of the studies focused on external sensors that do not have contact with babies' skin. Other studies, which used a contact sensor, continued using adhesives to place the sensors on babies. Moreover, it has been seen that smart textile oriented studies mostly focus on creating ECG sensors from textile material and use off-the-shelf stretch or piezo material for respiration sensor with a jacket or belt. The available research on smart textiles suggests a novel approach for adhesive-free textile-based RR sensors with a promise for clinical reliability and improved infant tolerance to the electrodes. 


\section{Materials and Methods}

\subsection{E-Textile Sensors}

Piezoresistive e-textile sensors provide improvement in wearability associated with enhanced breathability and comfort through the textile backing material [32].

\subsubsection{Design Selection Process of e-Textile Pressure Sensor}

As the research focus is to design e-textile pressure sensors to monitor the respiration cycle on newborn or premature babies, it was important for us to identify design elements of the proposed e-textile sensors, including geometry, fabric materials, and conductive textiles. Two different textile pressure sensors (with three different conductive materials) were designed and tested. Two integrating fabrics are Neutronyx (which is conductive non-woven microfiber with piezoresistive functionality for use in dynamic sensors to map and measure pressure variation) and Velostat (a nonwoven sheet of polymeric material composed of polyolefins impregnated with carbon black to make it electrically conductive with piezoresistive property) with different conductive material for sensor. Conductive fiber, conductive tape, and knit jersey were used as conductive materials. Those textile pressure sensors have piezoresistive properties which means their resistance changes depending on the changes in pressure. Those changes in resistance can be caught with a voltage divider circuit. Different sensor designs are shown in Figure 2.

The experimental system for comparative testing of the sensor prototypes consisted of three MG-995 servo motors and 3D printed parts. The MG-995 servo motors provide a maximum stall torque of $11 \mathrm{~kg} / \mathrm{cm}$ with an operating voltage of 4.8V-6.6V. Three sets of a cam, a mount, and a cylindrical container were 3D printed using Polylactic acid (PLA) and High Impact Polystyrene (HIPS) materials.

a) Sensor Design Selection: To imitate recurrent loading and unloading of pressure numerous times, a crank slider mechanism was employed, which loaded and unloaded the weights on the pressure sensors continuously. Three setups were prepared to operate independently. An Arduino emanated PWM signals to the servo motors while an external DC power supplied 5 volts of power. Another Arduino gathered the output data from the smart textile sensors.

The experimental setup consisted of six sensors, three sets of 2-ounce, 4-ounce, 6-ounce, 8-ounce, 10-ounce weights, an external DC supply, and two Arduino microcontrollers. Each experiment contained three sensors of the same sensor material, Neutronyx or Velostat, with one of the five weights. Fifteen minutes of data were acquired and stored using the Processing IDE. After that, the data was filtered and analyzed offline using Matlab.

Sensors were evaluated based on the parameters given below:

* Stability: the reliability of the sensor across a period. The same voltage reading should be measured for the same amount of applied pressure.

* Resolution: the instantaneous change in voltage per unit change in applied pressure.

* Settling Time: the time required for output to reach and remain within a given error band following some input stimulus.

* Rise and Fall Time: the time it takes for the leading edge of a pulse to rise from its minimum to maximum value and vice versa. Fast rise and fall mean better sensitivity.

* Hysteresis: the phenomenon where voltage lags behind the change in sensor, which happens when loading and unloading.

* Linearity: the measure to determine the variance between the actual value and observed value.

* Repeatability: the measure of the consistency of results for multiple experiments with the same criterion.

b) Sensor Validation: The linearity and repeatability results are summarized in Figure 3. The results showed that, for both sensors, the response of the jersey knit was the most consistent compared to the other conductive materials since the jersey knit has the highest repeatability feature. When the base fabrics were compared for frequency and rise/fall time, Velostat showed more consistency compared

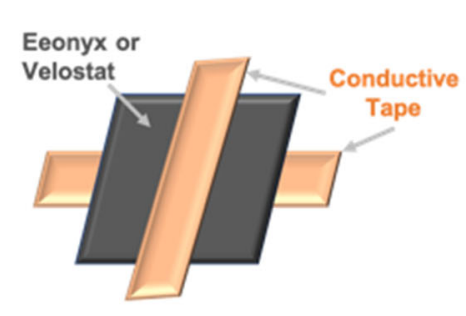

Conductive Tape

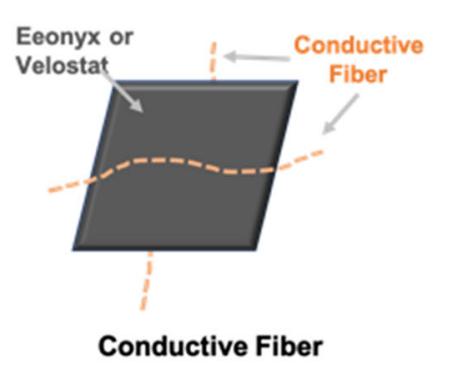

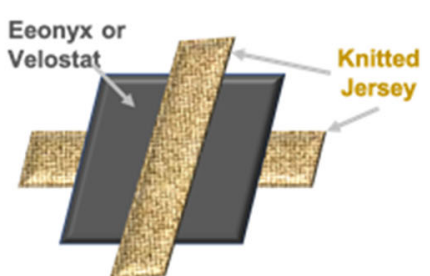

Knitted Jersey

Figure 2 The designs used in the material selection process 

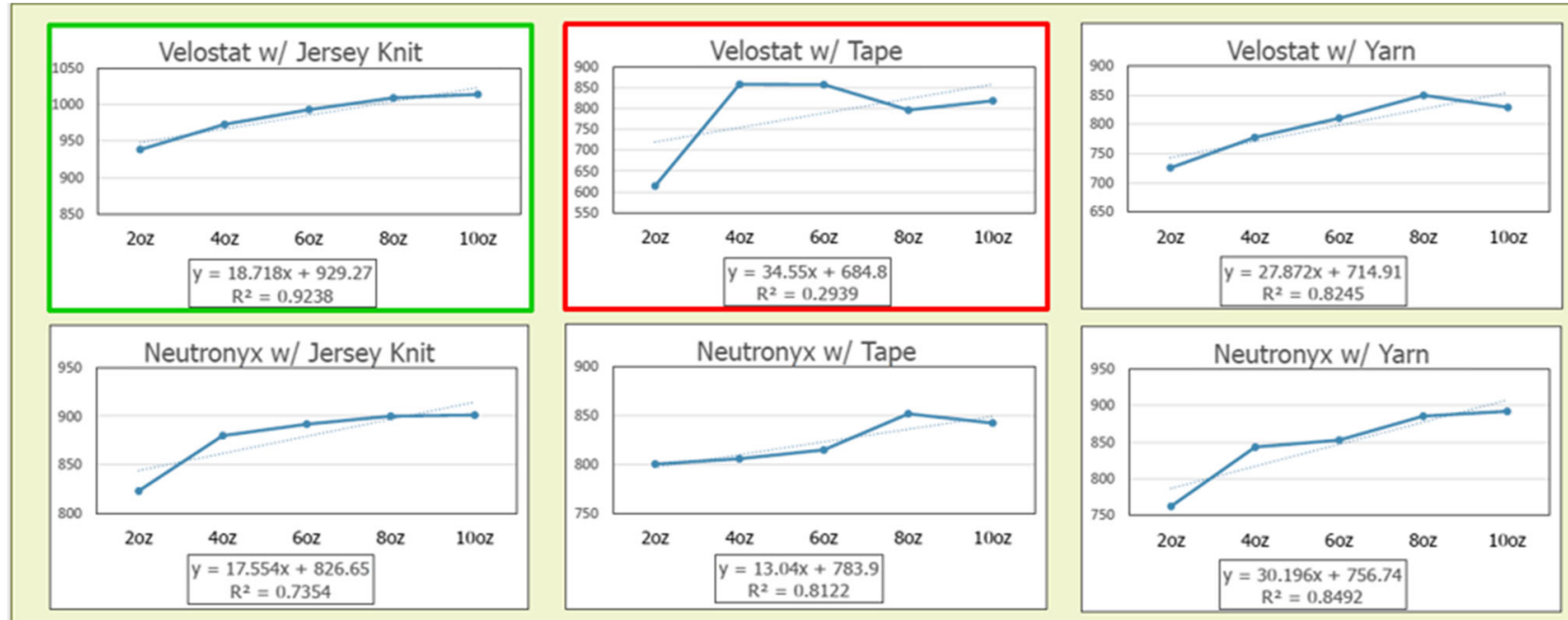

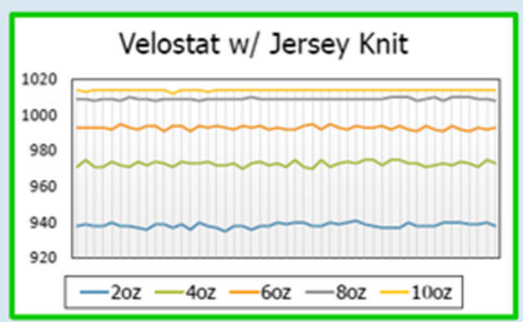

Average Standard Deviation: 0.951

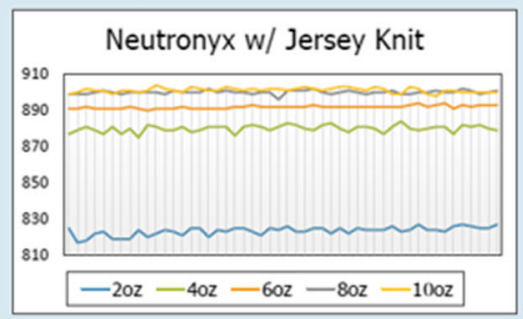

Average Standard Deviation: 1.472

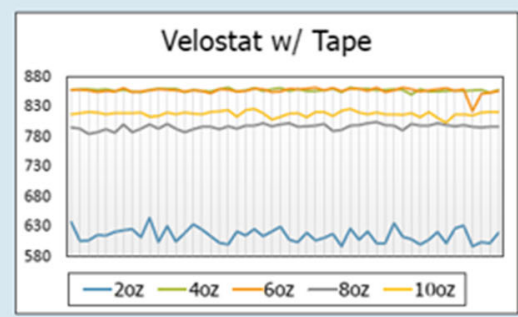

Average Standard Deviation: 5.714

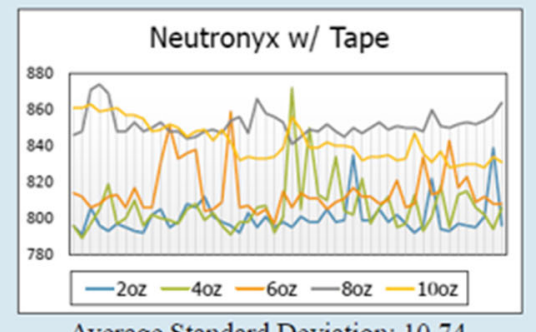

Average Standard Deviation: 10.74

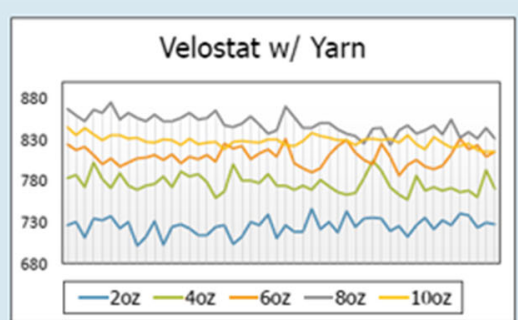

Average Standard Deviation: 9.926

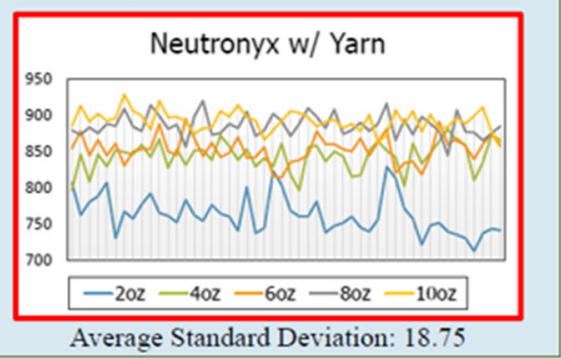

Figure 3 Linearity results (top) and repeatability results (bottom)

to Eeonyx. In addition, it has the maximum frequency at the mean value meaning that it has the fastest rise time. Additionally, the overall mean rise time of Velostat is lower than that of the Eeonyx. In terms of hysteresis, it is seen that Velostat with the conductive tape and Eeonyx with the jersey knit shows better performance. Since hysteresis, linearity, and repeatability are related to the accuracy, it can be claimed that Velostat with jersey knit have better accuracy than the others do.

\subsubsection{E-Textile Pressure Sensor Pad for Respiration Monitoring}

According to the results shown in Section 3.A.1.b, Velostat was selected as the pressure material, and jersey knit was selected as the conductive material. Then, two different pressure sensor pads were created to evaluate the textile pressure sensors for respiration monitoring.

Figure 4-a shows the hand-stitched, column-style design. The knitted jersey fabric was stitched as a column on a mattress topper material to power up the sensors. Then, the Velostat pressure sensors were placed. After that, two knitted jersey fabrics were stitched on the sensors as rows to read the analog data. In this design, the top sensor was placed on the chest and the bottom one was placed on the abdomen. Thus, monitoring of both chest and abdomen movements was sought.

Figure 4-b shows the embroidered, row-style design. It was embroidered using the ZSK JGVA Embroidery Machine [33]. The embroidery machine has three heads, $\mathrm{F}$ head, $\mathrm{W}$ head and $\mathrm{K}$ head, to perform electronic stitches. To create flatbed embroidery, which we used in our design, 


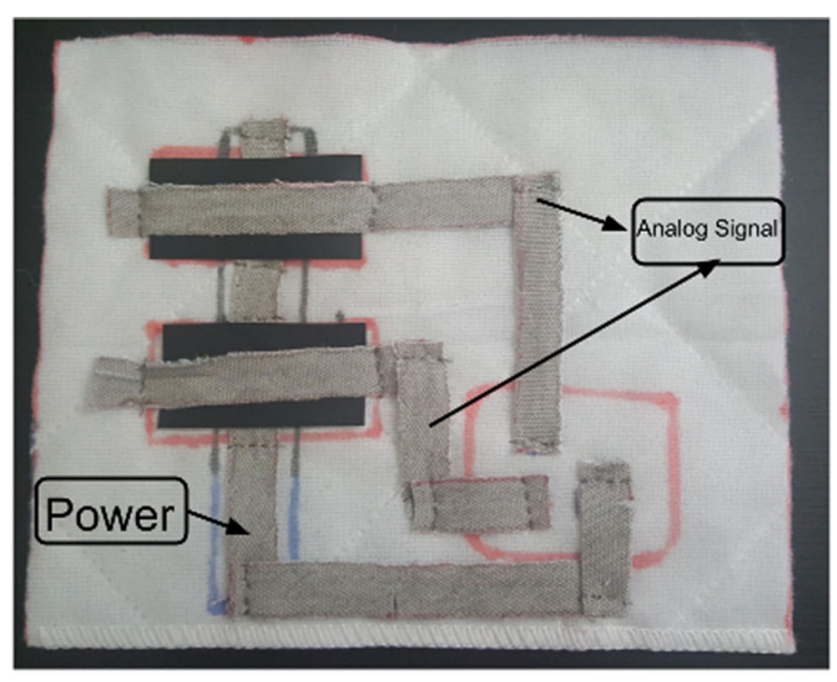

(a)

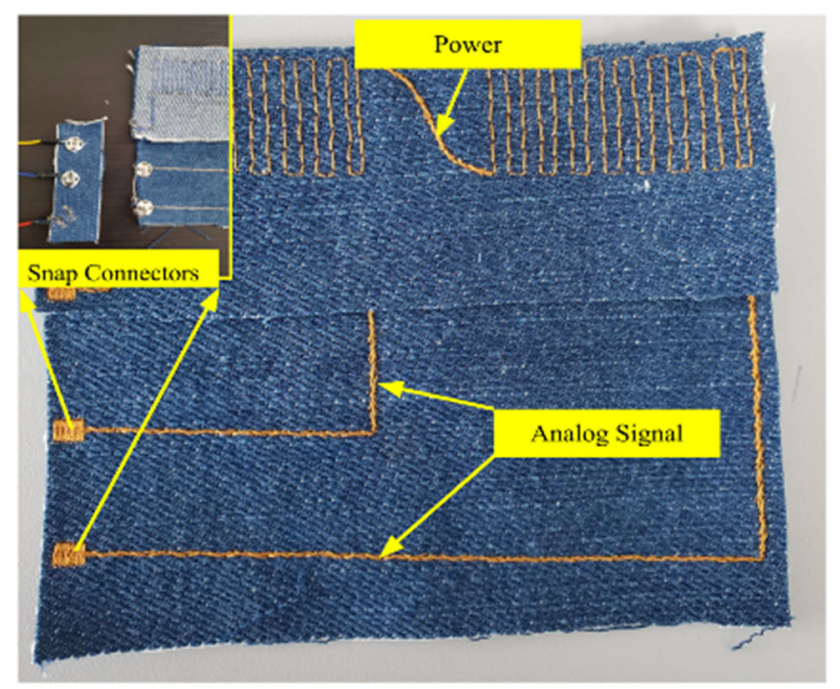

(b)

Figure 4 Sensor Pad Design (a) Hand-stitched column sensor, (b) Embroidered row sensor

the $\mathrm{F}$ head was used. It has special functions in its software to create area filling or comfort lines. To create our sensor design, the comfort line option was used. Since the connectivity was provided with an embroidered design, instead of knitted jersey fabric, a silver-plated conductive thread was used as the conductive material. In the design, at first two areas were created with conductive thread horizontally for collecting analog data. Then two Velostat pressure sensors were placed on top of those areas. After that, another two areas were created with conductive thread vertically and were placed on top of the Velostat sensors to power up the sensors. Figure 5 shows the open design before the sensor system is finished, the embroidery design, and the final assembly.

\subsection{Data Acquisition System}

The recording setup for testing the various pressure sensors is shown in Figure 6. The resistance of the sensors changes as the pressure is applied. This change in resistance is mapped to a change in voltage using a resistor divider with a fixed resistance of 10-kilo ohms. The potential difference between the resistor divider and ground is measured using the ADS1115 Analog to digital converter (ADC), which has a resolution of 16 bits when used in a single-ended configuration.

Two input channels of the quad-channel ADC are sampled at $125 \mathrm{~Hz}$, configured to use a full-scale input voltage range of $0-3.3 \mathrm{~V}$. The sampled ADC values transmitted to the recording computer using the onboard WiFi in the ESP32 over the MQTT protocol using the PubSubClient library. A mosquitto MQTT broker is run on the recording computer upon boot. A client python script using the Paho MQTT library was used to subscribe to the sensor published events and save log of the data into a .csv file at the end of the recording session.

\subsection{Signal Processing Methods}

We developed a signal-processing pipeline on Matlab (R2020a) to process experimental data and to analyze the results for the sensor characterization. Figure 7 shows the main processing blocks. The raw data represents the analog voltage across the sensor but in the form of a digital level set by the 16 bit ADC. Using the ADC conversion formula and accounting for the system voltage (3.3 Volt), we converted the ADC readings to voltage in the first step of the processing. We observed, on some occasions, sudden spikes and discontinuity in the signal (total $; 0.001)$. We used statistical methods to detect these outliers, remove them, and to replace them with the local means. For each data set, we set the global and local voltage thresholds at mean \pm 3 standard deviation. The local time window of 15 seconds was slid over the entire time course to implement these statistics. The sampling rate of the ADC was $(118 \pm 1) \mathrm{Hz}$. We resampled to $120 \mathrm{~Hz}$ and interpolated data to have a consistent sampling rate throughout all the data sets and to implement the same processing pipeline. In our experiments, the respiratory rate was 20-60 BrPM (breaths per minute). We designed an FIR bandpass filter $(\mathrm{FL}=0.01 \mathrm{~Hz}$ and $\mathrm{FH}=5 \mathrm{~Hz}$ ) using the Matlab fir1() function and applied it to the time series data using filter() function to remove the unwanted frequency. We have used Matlab's findpeak() function to find the peak locations of the signal, as shown in Figure 7. The instantaneous BrPM was estimated at each detected peak. 
Figure 5 Embroidered pressure sensor fabrication workflow:

(a) Digital design in software,

(b) Fabrication in the machine,

(c) Assembly of the embroidered pressure sensor using Velostat

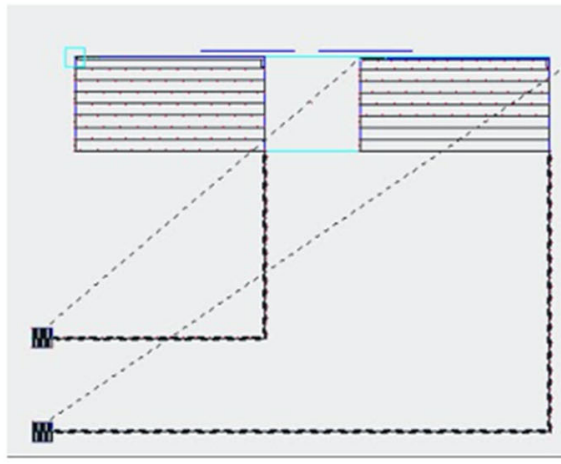

(a)

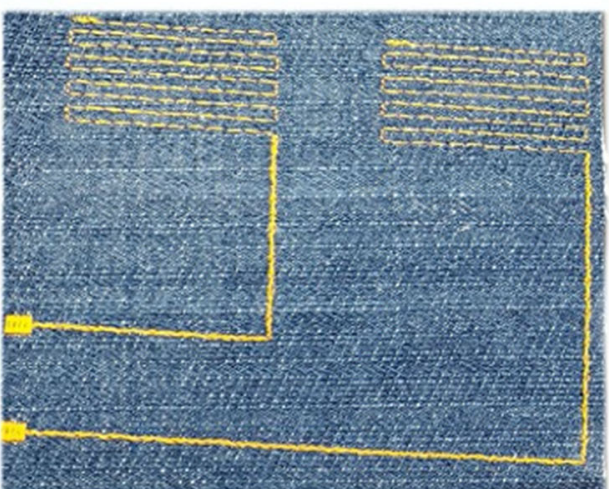

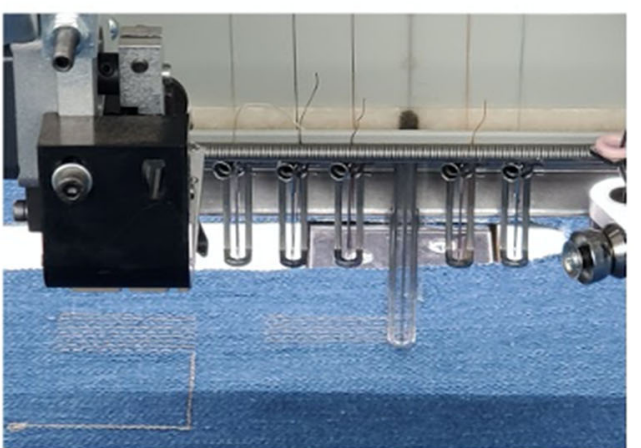

(b)
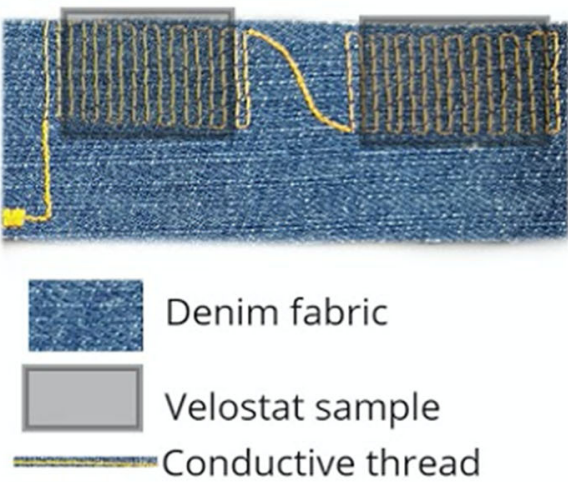

(c)

\section{Experimental Setup, Results and Discussion}

\subsection{Experimental Setup}

The sensor pads were placed on a Neonatal Care Patient Simulator Baby named Tory [34]. The baby's dimensions are shown in Figure 8. The sensor pad was created and placed according to the distance between lung points and the dimension of the Tory's chest.

Tory is connected to software called UNIR and can be programmed for different scenarios using UNI's user interface. Those scenarios include but are not limited to changing breathing rates, breathing patterns, heart rate, blood pressure level and other vital signals. Figure 8 also shows the sensor placement on Tory.

In our experiment to simulate fast, normal, and slow rates, different breathing rate settings were performed. For each sensor, those three different breathing rates were applied. The breathing rates were explained in Table 2 . Those scenarios were performed on both types of textile pressure sensor pads.

\subsection{Results}

Preprocessing of the Raw Sensor Signals

In all of our experiments, we were able to monitor the breathing rate of Tory with our hand-stitched and
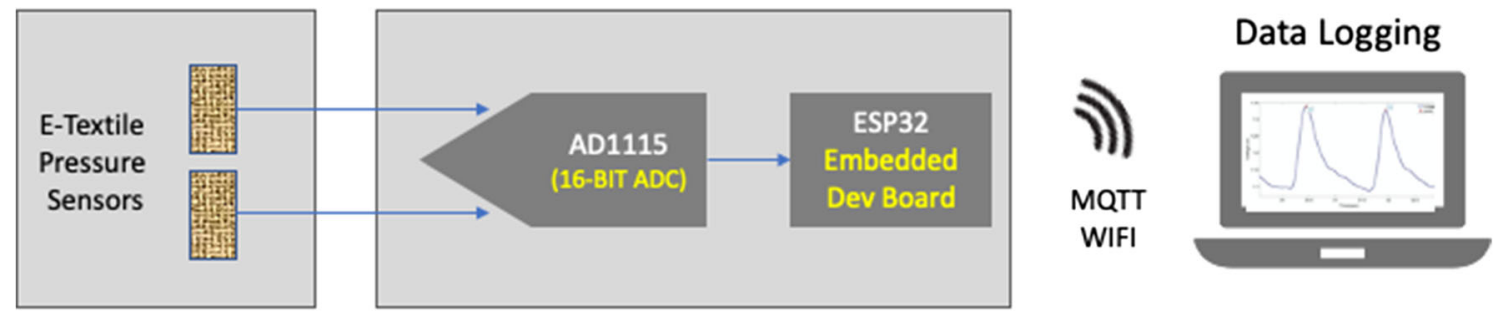

Figure 6 A simplified diagram of the data acquisition system 

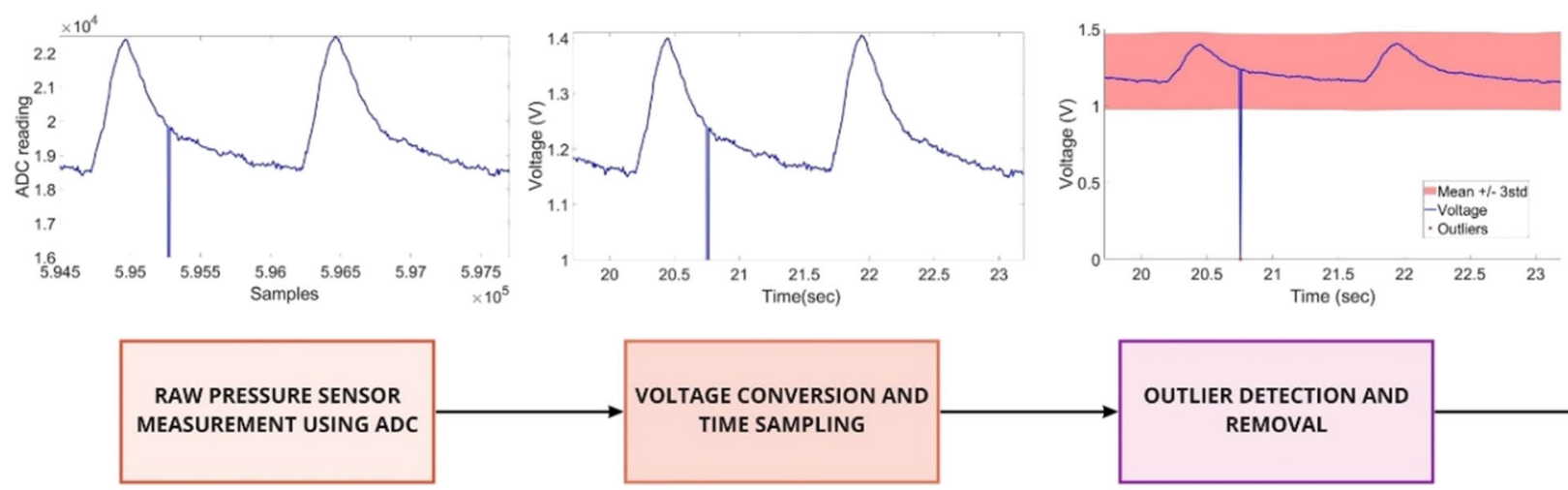

OUTLIER DETECTION AND REMOVAL
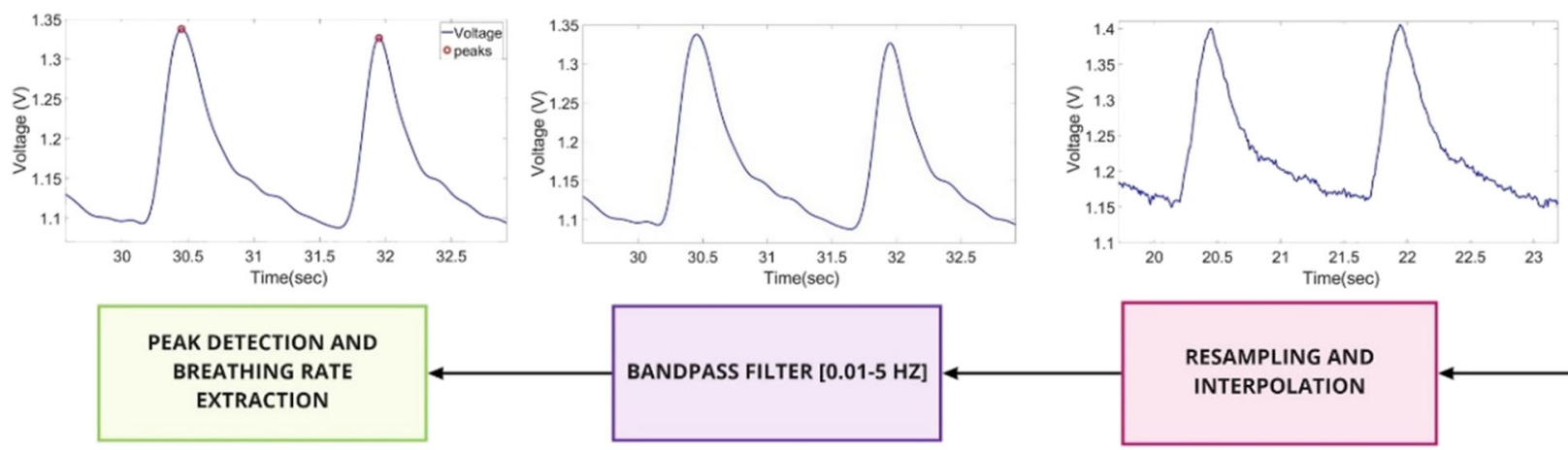

RESAMPLING AND INTERPOLATION

Figure 7 Signal-processing pipeline
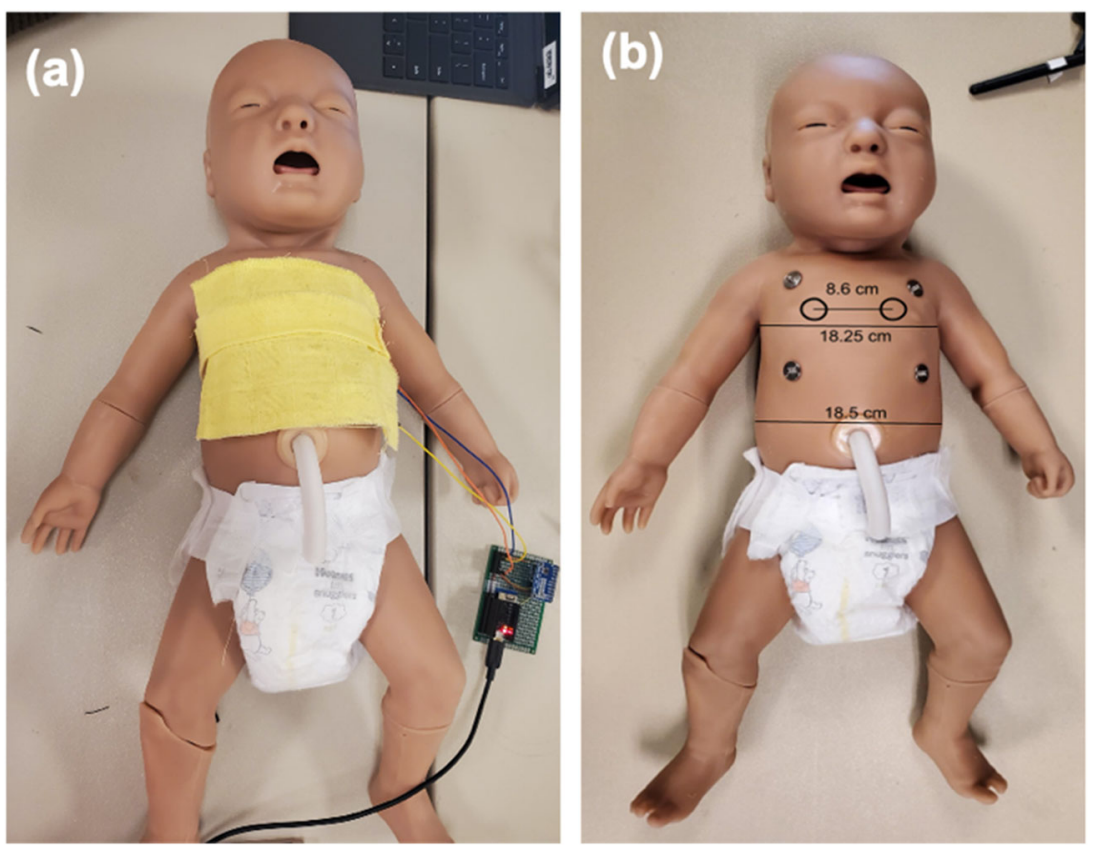

Figure 8 Tory - Tetherless and wireless full-term neonatal simulator. a) sensor placement and b) dimensions of the trunk

Table 2 Breathing scenarios

\begin{tabular}{llll}
\hline Parameter/Breathing Scenarios & Respiratory Rate & Respiratory Pattern & Duration \\
\hline Fast Breath & $60 \mathrm{BrPM}$ & normal & $5 \mathrm{~min}$ \\
Normal Breath & $40 \mathrm{BrPM}$ & normal & $5 \mathrm{~min}$ \\
Slow Breath & $20 \mathrm{BrPM}$ & normal & $5 \mathrm{~min}$ \\
\hline
\end{tabular}




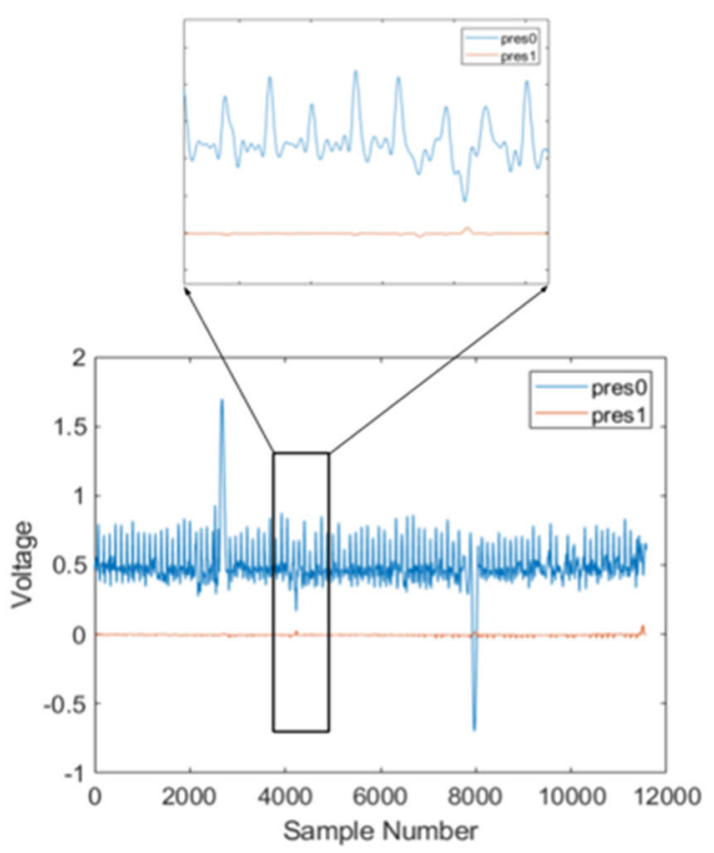

(a)

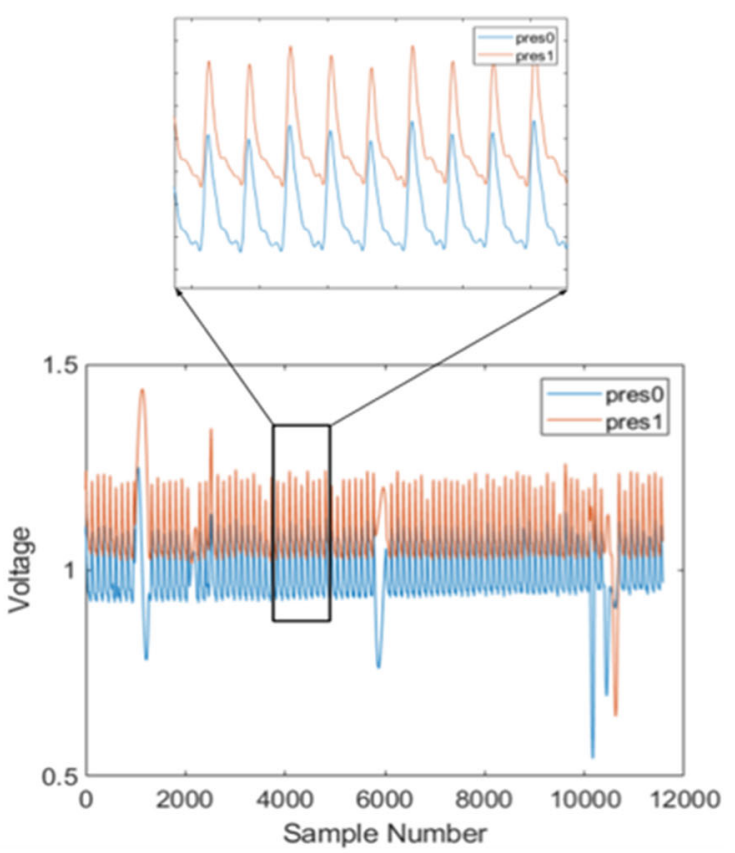

(b)

Figure 9 Raw signals from the textile sensors (a) Hand-stitched sensor, (b) Embroidered sensor

embroidered pressure sensors. The raw signal when a handstitched sensor and embroidered sensor was used in a 60 BrPM experimental setup is presented in Figure 9a and b, respectively. The quality of the raw data was measured over time, as shown in Figure 9, in two sections of the data sets of 30 second time windows.

Calculations of SNR

We can observe from the signals from the embroidered pressure sensor (see Figure 9b) show consistent changes associated with breathing when compared with the column sensor (see Figure 9a). We used a sliding window of 1.5 seconds to compute mean and standard deviation, thereby SNR, as shown in Figure 10a and $b$. We saw that the average SNR was $12 \pm 0.38 \mathrm{~dB}$ and $1 \pm 0.78 \mathrm{~dB}$ for the embroidered sensor and column sensor, respectively.
Calculation of RR, histograms, and rise/fall timings

We processed the raw data using the same processing pipeline to have consistent results described in Section 3. Figure 11 showed the rise-time and fall-time of two successive breaths when one of the sensors was used to calculate the RR of $20 \mathrm{BrPM}$. The rise-time was 0.2158 seconds and 0.1969 seconds, and the fall-time was 0.5690 seconds and 0.5649 seconds, respectively, for the two transitions. The two peaks $(1.358 \mathrm{~V}$ and $1.358 \mathrm{~V})$ occurred at the time 132.80 and $135.78 \mathrm{sec}$ respectively, which gives us the time interval of 2.98 seconds between the two peaks to compute an instantaneous BrPM of 60/2.98=20.12 BrPM.

We also calculated the rise-time and fall-time for the two sensors in the three experiments. The results are summarized in Table 3. From the Table, we see that both
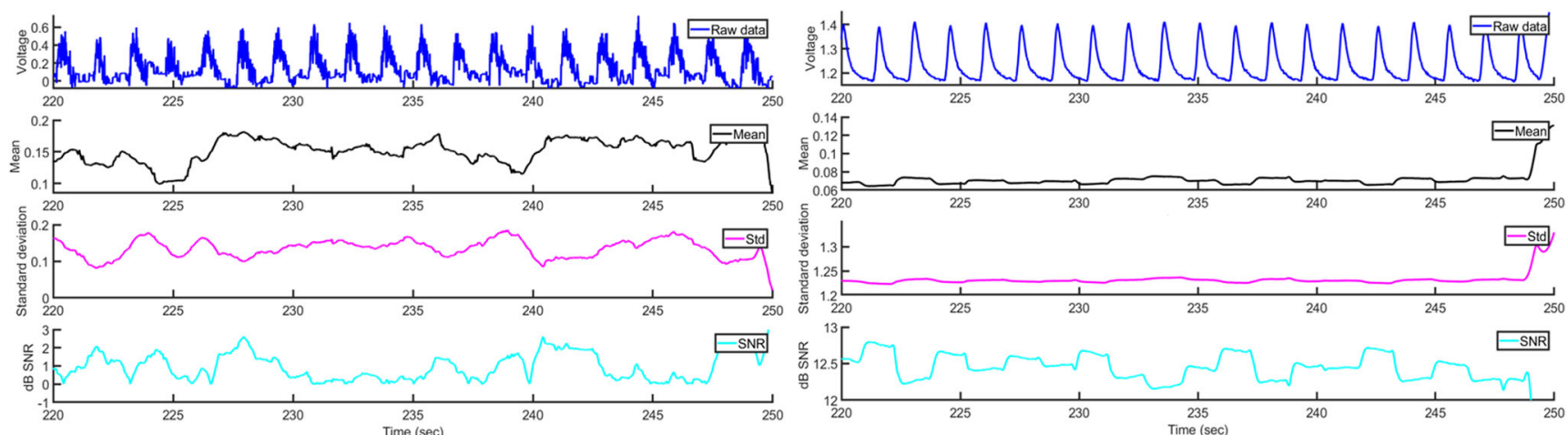

Figure 10 Hand-stitched column sensor (left), embroidered row sensor (right) 
Figure 11 The rise and fall timings in the respiration cycle

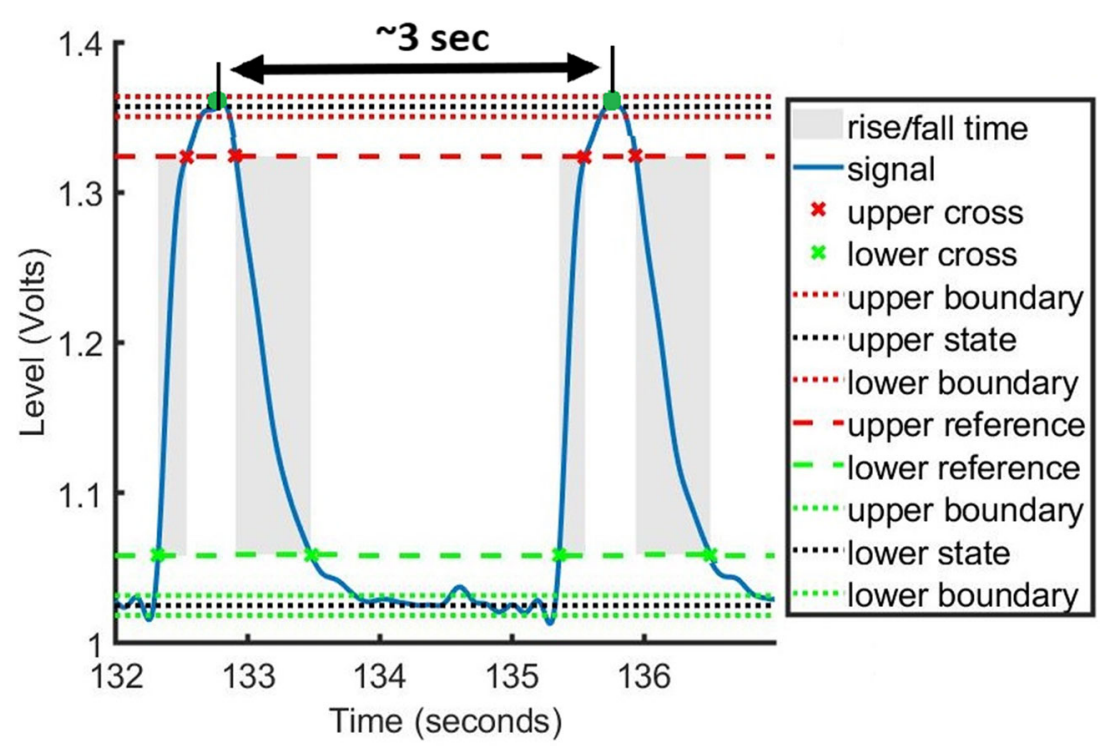

the rise-time and fall-time are decreased for all the sensors with increasing BrPM. For low BrPM, embroidered sensors are faster than column sensors; however, for high BrPM, column sensors are faster compared to embroidered sensors. This difference could be due to the sensitivity profile and the design structure of the two sensors.

Table 4 presents the mean and standard deviation of the calculated BrPM from all the experimental data. Figure 12 shows the histogram plots of the BrPM calculations for each sensor in the $60 \mathrm{BrPM}$ test case. From Table, we observed that embroidered sensors are consistently more accurate in estimating the BrPM compared to column sensors. We can also observe from the histogram plots that the embroidered sensor shows lower variability when compared to the column sensor.

We also wanted to compare the efficacy of our system with existing literature. For this, we compared the accuracy, root mean squared error and mean difference of our study with the state-of-art. Table 5 shows the comparison between previous studies and our study.

\subsection{Discussion}

\subsubsection{E-Textile Pressure Sensors}

The hand-stitched sensor was designed according to the dimensions of a CPR training baby mannequin. Baby Tory, which we used in experiments, has different dimensions shown in the Experimental Setup section. For this reason, the bottom sensor was placed on the abdomen part. Since there is very little or no movement on the abdomen, there is more noise, and the data from the bottom sensor was more erroneous.

The embroidered sensor was designed according to Tory's dimensions. However, when it was placed on Tory's chest, the left sensor was slightly shifted from the lung point, and this caused noisy data. The positioning of the sensor plays a crucial role with respect to the sensitivity of respiration detection.

It is also seen that the hand stitch is more susceptible to noises compared to embroidery. The connections between

Table 3 Rise time and fall time of the sensors

\begin{tabular}{|c|c|c|c|c|c|c|c|c|}
\hline \multirow[b]{3}{*}{ RR } & \multicolumn{4}{|c|}{ Column Sensor (Hand-stitched) } & \multicolumn{4}{|c|}{ Row Sensor (Embroidered) } \\
\hline & Top Sensor & & Bottom Senso & & Left Sensor & & Right Sensor & \\
\hline & $\begin{array}{l}\text { Mean Rise } \\
\text { Time (sec) }\end{array}$ & $\begin{array}{l}\text { Mean Fall } \\
\text { Time (sec) }\end{array}$ & $\begin{array}{l}\text { Mean Rise } \\
\text { Time (sec) }\end{array}$ & $\begin{array}{l}\text { Mean Fall } \\
\text { Time (sec) }\end{array}$ & $\begin{array}{l}\text { Mean Rise } \\
\text { Time (sec) }\end{array}$ & $\begin{array}{l}\text { Mean Fall } \\
\text { Time (sec) }\end{array}$ & $\begin{array}{l}\text { Mean Rise } \\
\text { Time (sec) }\end{array}$ & $\begin{array}{l}\text { Mean Fall } \\
\text { Time (sec) }\end{array}$ \\
\hline $60 \mathrm{BrPM}$ & 0.0712 & 0.0754 & 0.0605 & 0.0694 & 0.0838 & 0.2574 & 0.0818 & 0.3907 \\
\hline $40 \mathrm{BrPM}$ & 0.1422 & 0.1161 & 0.0154 & 0.0217 & 0.1355 & 0.3273 & 0.1403 & 0.4893 \\
\hline $20 \mathrm{BrPM}$ & 0.322 & 0.3693 & 0.4208 & 0.2544 & 0.261 & 0.5643 & 0.2436 & 0.6782 \\
\hline
\end{tabular}


Table 4 Mean and standard deviation values for both sensors

\begin{tabular}{lllll}
\hline & \multicolumn{2}{l}{$\begin{array}{l}\text { Column Sensor (Hand-stitched) } \\
\text { Rop Sensor } \\
(\text { meanmean } \pm \text { Std) }\end{array}$} & $\begin{array}{l}\text { Bottom } \\
\text { Sensor } \\
(\text { meanmean } \pm \text { Std) }\end{array}$ & \multicolumn{2}{l}{$\begin{array}{l}\text { Row Sensor (Embroidered) } \\
\text { (meanmean } \pm \text { Std) }\end{array}$} & $\begin{array}{l}\text { Rensor } \\
\text { Sensor } \\
(\text { meanmean } \pm \text { Std) }\end{array}$ \\
\hline $60 \mathrm{BrPM}$ & $60.3168 \pm 0.9481$ & $60.8529 \pm 1.1864$ & $59.9783 \pm 0.5257$ & $60.0073 \pm 0.5444$ \\
$40 \mathrm{BrPM}$ & $40.3067 \pm 0.6238$ & $40.4103 \pm 0.598$ & $39.9846 \pm 0.285$ & $39.9941 \pm 0.2933$ \\
$20 \mathrm{BrPM}$ & $19.9793 \pm 0.4365$ & $20.143 \pm 0.4959$ & $20.0039 \pm 0.4128$ & $19.982 \pm 0.2059$ \\
\hline
\end{tabular}

Figure 12 Histogram plots of both sensors
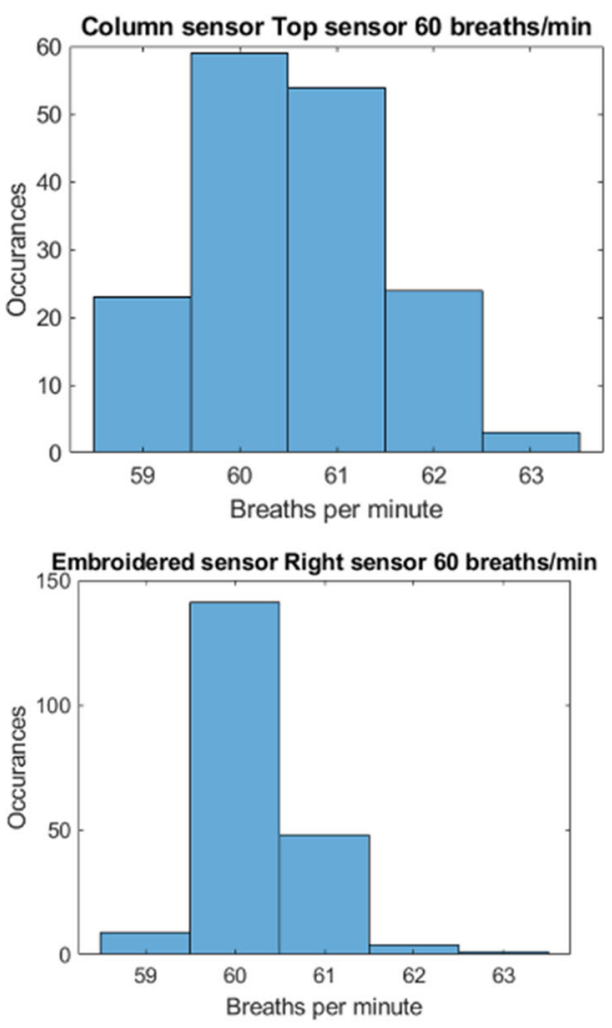
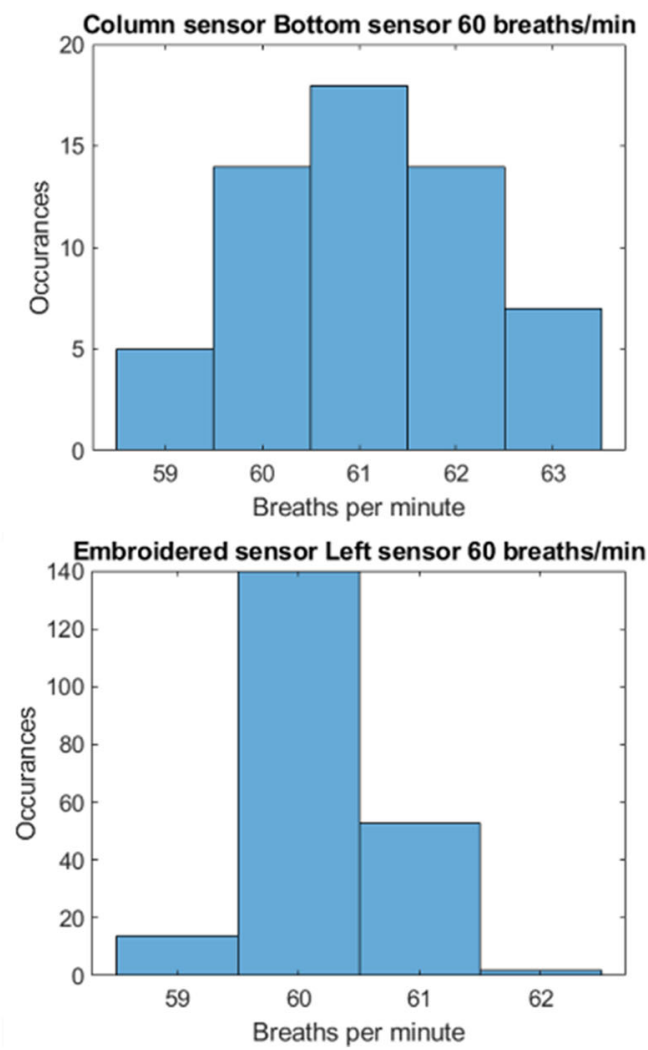

Table 5 Comparison between state-of-art

\begin{tabular}{|c|c|c|c|c|c|}
\hline Study & Sensor type & Sensor & $\begin{array}{l}\text { Root mean } \\
\text { squared } \\
\text { error }\end{array}$ & Accuracy $(\%)$ & $\begin{array}{l}\text { Mean dif- } \\
\text { ference } \\
\text { error } \pm S T D\end{array}$ \\
\hline Cay et al. (This research) & & $\begin{array}{l}\text { Textile pressure sensor } \\
\text { on the body }\end{array}$ & 0.285 & 99.37 & $0.0154 \pm 0.285$ \\
\hline \multirow[t]{2}{*}{ Hariyanti et al. [20] } & & $\begin{array}{l}\text { Wearable fiber optic sen- } \\
\text { sor on the diaper }\end{array}$ & N/A & 99.75 & N/A \\
\hline & & sensor on the body & N/A & N/A & $0.3 \pm 0.95$ \\
\hline Ambili et al. [21] & & Camera & N/A & 98 & N/A \\
\hline Sun et al. [22] & & $\begin{array}{l}\text { Camera and sensor on } \\
\text { the mattress }\end{array}$ & 6.10 & N/A & N/A \\
\hline Braun et al. [23] & External sensors & Camera & N/A & N/A & $0.2 \pm 2.3$ \\
\hline
\end{tabular}


the jersey fabric and the conductive thread can cause disconnection momentarily. In addition, determining the stitch and step length in the hand stitch is hard, so different lengths can cause different resistances. On the other hand, in embroidery, the stitch and step length are programmed with the software, so the resistance occurs the same at every point. Also, all conductive threads are connected from beginning to end, so there is no possibility of disconnection.

Table 5 shows that on-body sensors (our results and results of the other on-body sensors $[16,20])$ have higher accuracy and lower error than the external sensors (i.e. camera methods or sensors on the mattress) meaning that on-body sensors provide more reliable monitoring. In our search, we cannot find any study that applies all three measurements, root mean squared error, accuracy and mean difference error together. It also can be seen from Table 5 that our results showed better accuracy and lower error than the state-of-art.

\subsubsection{Analog Acquisition and ADC selection}

The analog front-end chosen for the study to acquire the sensor data was a resistor divider using one of the piezoresistive sensors. While the analog acquisition was easy to test and implement, it had increased noise as the measurement is tied to supply voltage accuracy and increased vulnerability to time and temperature drifts in the second fixed resistor. Further, there is a DC bias in the measured voltage over which $\mathrm{AC}$ variations associated with the piezoresistive sensor are superimposed. The use of a 16-bit ADC helps improve voltage measurement resolution to pick up the sensor's AC variations. Using a Wheatstone bridge as the analog front-end can also help address reference resistor drift through ratio metric measurements. The differential bridge voltage generated by the Wheatstone bridge interface can be directly measured by ADC, which can also allow for even amplification of voltages between $\pm 0.256 \mathrm{~V}$ to full-scale range using the inbuilt programmable gain amplifier enabling better detection of shallow breaths.

\subsubsection{Experimental Setup}

The experiments for detecting various breathing rates showed promising results. In future studies, we are planning to create different testing conditions, such as a more diverse number of breathing rates and variable breathing patterns such as apnea and hyperventilation. The initial promising results also lead us to make more experiments on preterm babies. In future, we aim to test the system on premature baby mannequins, healthy infants, and preterm babies with minor changes in the chest belt design tailored to the specific requirements of preterm babies.

\subsubsection{Noise and Packet Loss}

Since the MQTT client library used on the data acquisition system only supported quality of service 0 (QoSO) transmission, there were a few packet loss events associated with momentary disconnections in the $\mathrm{WiFi}$ connection status. Since QoS0 waits for the acknowledged packets from the MQTT broker, certain messages are lost during momentary wireless disconnections. We will address this issue by upgrading the present MQTT library to handle QoS 1 asynchronous publish services, which can help retrieve the messages lost from momentary packet losses. Additionally, using network synchronized RTC timing and microSD logging; we can ensure the reconstruction of missing samples associated with extended network outages after boot.

\subsubsection{Signal Processing}

We implemented various built-in signal processing and peak detection functions of Matlab to design the data processing pipeline and to test our system in this work. We have measured the SNR of the raw experimental data. The SNR was dependent on the sensor placement on Tory. In certain experimental conditions, when the sensor was not properly placed, the SNR dropped significantly, and the processing pipeline failed to accurately detect the peaks. In the future, we will develop a robust algorithm for the end-to-end data processing to detect peaks and to estimate the breath rate in real-time on the embedded platform that would be more suitable for our textile pressure sensor. The algorithm will also fuse signals from all the sensors located around the body to minimize the error rate and study the breath dynamic.

\section{Conclusion}

This is a collaborative research paper involving the areas of smart textiles, textile design, biomedical engineering, electrical engineering, computer engineering, pediatrics, and neonatology. The traditional monitoring systems in NICU have disadvantages due to the use of adhesive and wired electrodes. Those electrodes can harm babies and cause irritation and discomfort. In addition, the respiratory monitoring is often unreliable because the respiration signal is extracted from EEG and pulse oximetry. The aim of this project was to design and validate an unobtrusive respiration monitoring system that consists of e-textile pressure sensors for monitoring the respiratory changes in the babies in NICU. The design of an etextile sensor was a two-step process; firstly, we conducted a prototype design comparison study that defined the 
materials and geometry for the sensor, and secondly, we designed two e-textile pressure sensors for respiration rate monitoring. To validate the system, a high-fidelity newborn simulation baby was used, and various breathing rates were recorded. Our experimental work demonstrates that the textile pressure sensors monitor the different breathing rates effectively. Also, the SNR and rise/fall times showed that the embroidered sensor had better performance and consistency than the hand-stitched sensor. Major challenges include the positioning of the pressure sensor on exact lung points and data loss due to poor connectivity and wireless communication. In future research, a developed peak detection algorithm will be applied to the data. Also, to place the pressure sensor more efficiently, a chest belt will be designed. This will be followed by the design of a user interface which can control the system wirelessly.

Acknowledgments The authors thank Dhaval Solanki, Michaela Bellisle, Himanshu Mishra, Kiran Thakur, Sarah Leighton, Madeline Setear, and Isabella Lapolito for their contribution to sensor design and data collection. Gozde Cay is supported by Turkish Ministry of National Education for her $\mathrm{PhD}$ research.

\section{References}

1. Preterm birth, https://www.who.int/en/news-room/fact-sheets/ detail/preterm-birth (208).

2. Murković, I., Steinberg, M.D., \& Murković, B. (2003). Sensors in neonatal monitoring: current practice and future trends. Technology and health care : official journal of the European Society for Engineering and Medicine, 11(6), 399-412.

3. Joshi, R., Bierling, B., Feijs, L., van Pul, C., \& Andriessen, P (2019). Monitoring the respiratory rate of preterm infants using an ultrathin film sensor embedded in the bedding: a comparative feasibility study. Physiological measurement, 40(4), 45003.

4. Jorge, J., Villarroel, M., Chaichulee, S., Green, G., McCormick, K., \& Tarassenko, L (2019). Assessment of signal processing methods for measuring the respiratory rate in the neonatal intensive care unit. IEEE Journal of Biomedical and Health Informatics, 23(6), 2335-2346.

5. Marchionni, P., Scalise, L., Ercoli, I., Palazzi, M.L., \& Carnielli, V P (2016). Effect of limbs' motion on pulse oximetry in preterm infants. In 2016 IEEE International Symposium on Medical Measurements and Applications (MeMeA) (pp. 1-6). IEEE.

6. Lund, C. (2014). Medical adhesives in the NICU. Newborn and Infant Nursing Reviews, 14(4), 160-165.

7. August, D.L., New, K., Ray, R.A., \& Kandasamy, Y (2018). Frequency, location and risk factors of neonatal skin injuries from mechanical forces of pressure, friction, shear and stripping: a systematic literature review. Journal of Neonatal Nursing, 24(4), 173-180.

8. Edsberg, L.E., Black, J.M., Goldberg, M., McNichol, L., Moore, L., \& Sieggreen, M (2016). Revised National Pressure Ulcer Advisory Panel pressure injury staging system: revised pressure injury staging system. Journal of Wound, Ostomy, and Continence Nursing, 43(6), 585.

9. McNichol, L., Lund, C., Rosen, T., \& Gray, M (2013). Medical adhesives and patient safety: state of the scienceconsensus statements for the assessment, prevention, and treatment of adhesive-related skin injuries. Journal of Wound Ostomy \& Continence Nursing, 40(4), 365-380.

10. Schlüer, A.-B. (2017). Pressure ulcers in maturing skin-a clinical perspective. Journal of tissue viability, 26(1), 2-5.

11. Nist, M.D., Rodgers, E.A., Ruth, B.M., Bertoni, C.B., Bartman, T., Keller, L.A., Dail, J.W., Gardikes-Gingery, R., \& Shepherd, E G (2016). Skin rounds: a quality improvement approach to enhance skin care in the neonatal intensive care unit. Advances in Neonatal Care, 16, S33-S41.

12. Broom, M., Dunk, A.M., \& E Mohamed, A-L (2019). Predicting Neonatal Skin Injury: The First Step to Reducing Skin Injuries in Neonates. Health Services Insights, 12, 1178632919845630.

13. The Neonatal Intensive Care Unit (NICU). [Online]. Available: https://www.stanfordchildrens.org/en/topic/default? id=the-neonatal-intensive-care-unit-nicu-90-P02389.

14. Equipment That Is Used in the NICU. [Online]. Available: https://www.stanfordchildrens.org/en/topic/default? id=equipment-that-is-used-in-the-nicu-90-P02358.

15. Johnson, K. R., Hagadorn, J. I., \& Sink, D. W. (2017). Alarm safety and alarm fatigue. Clinics in Perinatology, 44(3), 713-728.

16. Chung, H. U., Kim, B. H., Lee, J. Y., Lee, J., Xie, Z., Ibler, E. M., Lee, K., Banks, A., Jeong, J. Y., \& Kim, J. (2019). Binodal, wireless epidermal electronic systems with in-sensor analytics for neonatal intensive care, Science, 363(6430).

17. Atallah, L., Serteyn, A., Meftah, M., Schellekens, M., Vullings, R., Bergmans, J. W. M., Osagiator, A., \& Oetomo, S.B. (2014). Unobtrusive ECG monitoring in the NICU using a capacitive sensing array, Physiological measurement, 35(5), 895.

18. Sato, S., Ishida-Nakajima, W., Ishida, A., Kawamura, M., Miura, S., Ono, K., Inagaki, N., Takada, G., \& Takahashi, T. (2010). Assessment of a new piezoelectric transducer sensor for noninvasive cardiorespiratory monitoring of newborn infants in the NICU, Neonatology, 98(2), 179-190.

19. Raj, A. A., Preejith, S. P., Raja, V. S., Joseph, J., \& Sivaprakasam, M. (2018). Clinical Validation of a Wearable Respiratory Rate Device for Neonatal Monitoring. In 2018 40th Annual International Conference of the IEEE Engineering in Medicine and Biology Society (EMBC) (pp. 1628-1631).

20. Hariyanti, K., Devara, F. N., Aisyah, K. V., Nadia, A. W., \& Purnamaningsih, R. W. (2019). Design of a wearable fiber optic respiration sensor for application in NICU incubators. In AIP Conference Proceedings, (Vol. 2092, No. 1, pp. 20002). AIP Publishing LLC.

21. Ambili, A. K., Kumar, R. K., Rajan, A. P., Nag, A., \& Poovaya, S. Non-contact respiratory rate monitoring with raybaby in an nicu: An observational study.

22. Sun, Y., Wang, W., Long, X., Meftah, M., Tan, T., Shan, C., Aarts, R. M., \& de With, P.H.N. (2019). Respiration monitoring for premature neonates in nicu, Applied Sciences, 9(23). [Online]. Available: https://www.mdpi.com/2076-3417/9/23/5246.

23. Braun, F., Lemkaddem, A., Moser, V., Dasen, S., Grossenbacher, O., \& Bertschi, M. (2018). Contactless respiration monitoring in real-time via a video camera. In H. Eskola, O. Väisänen, J. Viik, \& J. Hyttinen (Eds.) EMBEC \& NBC 2017 (pp. 567-570). Singapore: Springer.

24. Meyer, J., Arnrich, B., Schumm, J., \& Troster, G. (2010). Design and modeling of a textile pressure sensor for sitting posture classification, IEEE Sensors Journal, 10(8), 1391-1398.

25. Locher, I., Kirstein, T., \& Tröster, G. (2005). Temperature profile estimation with smart textiles. In Proceedings of the International Conference on Intelligent textiles, Smart clothing, Well-being, and Design (pp. 19-20). Tampere: Citeseer.

26. Plant, L., Noriega, B., Sonti, A., Constant, N., \& Mankodiya, K. (2016). Smart E-textile gloves for quantified measurements in movement disorders. In 2016 IEEE MIT Undergraduate Research Technology Conference (URTC) (pp. 1-4). IEEE. 
27. Van Langenhove, L., Hertleer, C., Westbroek, P., \& Priniotakis, J. (2007). 6 - Textile sensors for healthcare. In L. B. T. S. T. f. M. Van Langenhove and Healthcare (Ed.) Woodhead Publishing Series in Textiles (pp. 106-122). Woodhead Publishing. [Online]. Available: http://www.sciencedirect. com/science/article/pii/B9781845690274500069.

28. Bouwstra, S., Chen, W., Feijs, L., \& Oetomo, S.B. (2009). Smart jacket design for neonatal monitoring with wearable sensors. In 2009 Sixth International Workshop on Wearable and Implantable Body Sensor Networks (pp. 162-167). IEEE.

29. Piccini, L., Ciani, O., Grönvall, E., Marti, P., \& Andreoni, G. (2008). New monitoring approach for neonatal intensive care unit, in 5th International Workshop on Wearable Micro and Nanosystems for Personalized Health (pp. 6).

30. Chen, W., Dols, S., Oetomo, S. B., \& Feijs, L. (2010). Monitoring body temperature of newborn infants at neonatal intensive care units using wearable sensors, in Proceedings of the Fifth International Conference on Body Area Networks (pp. 188-194).
31. Chen, H., Bao, S., Lu, C., Wang, L., Ma, J., Wang, P., Lu, H., Shu, F., Bambang Oetomo, S., \& Chen, W. (2020). Design of an integrated wearable multi-sensor platform based on flexible materials for neonatal monitoring, IEEE Access, 8, 23 732-23 747.

32. Aigner, R., Pointner, A., Preindl, T., Parzer, P., \& Haller, M. (2020). Embroidered Resistive Pressure Sensors: A Novel Approach for Textile Interfaces, in Proceedings of the 2020 CHI Conference on Human Factors in Computing Systems (pp. 1-13). ser. CHI '20. New York, Association for Computing Machinery. [Online]. Available: https://doi.org/10.1145/3313831.3376305.

33. ZSK Technical Embroidery Machines. [Online]. Available: https://www.zskmachines.com/.

34. Tory - Tetherless and Wireless Full-term Neonatal Simulator. [Online]. Available: https://www.gaumard.com/tory.

Publisher's Note Springer Nature remains neutral with regard to jurisdictional claims in published maps and institutional affiliations. 